\title{
Fraseologismos con el color rojo en eslovaco y español en las clases de ELE
}

\author{
NinA MocKOvÁ \\ Universidad de Economía de Bratislava \\ nina.mockova@euba.sk
}

\begin{abstract}
Resumen: El presente artículo se centra en las unidades fraseológicas con el componente cromático «rojo» en eslovaco y español. Las analiza desde el aspecto formal, semántico, traductológico y didáctico. Desde el aspecto formal, compara las estructuras más frecuentes de estos cromatismos en ambos idiomas. Desde el aspecto semántico, compara las connotaciones que estas expresiones pluriverbales tienen en estos dos idiomas y las contrasta con las connotaciones universales del color rojo. Desde el aspecto traductológico, compara las unidades fraseológicas a nivel interlingüístico, examinando los equivalentes traductológicos. El artículo presenta una serie de actividades con implicaciones didácticas que podrían ser empleadas en una clase de ELE para enseñar los fraseologismos españoles a los estudiantes eslovacos.
\end{abstract}

Palabras clave: eslovaco, español, rojo, fraseología, didáctica.

\section{Slovak and Spanish idioms with red colour and its didactic application}

Abstract: This article is aimed on idioms with a chromatic element in their structure the red colour. It compares and contrasts Slovak idioms with red colour with the Spanish ones, regarding the aspect of their formal structure, semantic connotations and how to translate them, focusing on those with equivalents and those without equivalents. The aim of this article is to find out the common features and differences between these chromatic idioms in Slovak and Spanish according to the defined criteria, as well as to present its didactic applications to bring this topic to Slovak students of Spanish as a foreign language.

Key words: Slovak, Spanish, red, phraseology, didactics.

\section{Introducción}

El hecho de observar la naturaleza, las relaciones interpersonales, algunas experiencias repetidas, el comportamiento humano y animal, incitó cierta predilección por denominar tales fenómenos y expresarlos de otra manera. Así empezaron a nacer las primeras sabidurías populares, comparaciones, frases hechas o refranes que reflejaban verdades universales, o denominaban cualidades o características humanas (mayoritariamente) negativas de una forma metafórica. Quizás la obra más famosa que recoge historias de esta índole son las Fábulas de Esopo, del siglo VI a. de C., en las que las cualidades humanas negativas están proyectadas a través de los animales. A lo largo de la Historia y con el uso repetitivo, muchas imágenes figurativas o sabidurías populares han pasado a ser universales y diferentes culturas las han adoptado en su fraseología.

Debido a ello, es posible denominar a una persona falsa comparándola con animales asociados con la falsedad (la serpiente, el zorro o el gato). Es una imagen común en 
varios idiomas: astuto como un zorro (en español), prefikaný ako lišska (en eslovaco), (as) sly as a fox (en inglés), furbo come una volpe (en italiano), rusé comme un renard (en francés), falsch wie eine Schlange/Katze (en alemán). Todos estos idiomas han adoptado la imagen de un zorro como sinónimo de una persona falsa, excepto el alemán que asocia este fenómeno con una serpiente o un gato.

Varias personas se dedicaron a la recopilación de este tipo de expresiones peculiares por ser interesantes, originales, diferentes del lenguaje común. Las primeras obras son de la Edad Media, anónimas o con autoría. Aunque no se trata de investigaciones lingüísticas propiamente dichas, sino de recopilaciones a nivel de diccionarios, constituyen una rica fuente del estudio de un idioma.

Durante siglos, todas estas expresiones peculiares, figurativas solían englobarse bajo el término de paremiología, hasta que, a principios del siglo XX, el lingüista suizo, Charles Bally, propuso una división de expresiones figurativas en dos campos básicos: el núcleo o el centro y la periferia o el margen de la esfera del estudio lingüístico. Ch. Bally utilizó como primero el término fraseología en el sentido conocido hoy. El núcleo del estudio fraseológico lo definió a través de las expresiones de carácter no oracional, a nivel del sintagma o palabra y en la periferia de la fraseología ubicó las expresiones de carácter oracional (oraciones simples o compuestas), hallándose este tipo de expresiones en el eje común entre la fraseología y la paremiología. Por lo tanto, la esfera del estudio de la paremiología es más amplia que la de la fraseología, ya que engloba también los géneros folklóricos de la cultura popular, mientras que la fraseología se centra en frases y construcciones sintagmáticas de índole gramatical (Mlacek, 1984, Spišiaková, 2003). A pesar de las múltiples definiciones del objeto de estudio de la fraseología, estamos de acuerdo con Čermák, que no existe una sola definición que podríamos llamar «global» aplicable a todos los tipos de unidades fraseológicas, debido a la complejidad formal y funcional de las mismas (Čermák, 2007: 83).

\section{Fraseología en Eslovaquia}

La primera mención paremiológica en Eslovaquia proviene del siglo XIX, del Romanticismo, cuando se empiezan a resaltar los valores nacionales. Esto sucede a raíz de las luchas de las pequeñas naciones europeas por conseguir el estatus de estados autónomos. Záturecký recopiló los dichos, proverbios, refranes eslovacos populares y los publicó en el libro Slovenské príslovia, porekadlá a úslovia (1897).

La teoría y la investigación fraseológica eslovaca y checa (durante más de 70 años un país - Checoslovaquia) ha estado en sus principios bastante influenciada por las ideas de la escuela lingüística rusa y las mayores investigaciones se llevaron a cabo en los años 70 y 80 del siglo XX. En este sentido, se entiende la fraseología como una disciplina que abarca muchas cuestiones de la lexicología, aunque no forma parte de ella. Sostienen la autonomía de la fraseología entre las disciplinas lingüísticas, pero consideran que no es posible separarla por completo de ellas.

En general, los fraseólogos eslovacos concuerdan en definir el objeto de estudio de la fraseología a través de tres tipos básicos de unidades: unidades fraseológicas mínimas que constan de dos palabras, unidades con estructura de un sintagma que pueden representar todas las clases de palabras y unidades con estructura oracional, simple o compuesta (Mlacek, 1984: 56). También concuerdan en definir la fraseología como 
una disciplina lingüística específica, relativamente autónoma, cuyo objeto de estudio son las unidades pluriverbales lexicalizadas, ante todo aquellas con el sentido metafórico (Mlacek, 1984; Škultéty, 1991). Otro lingüista eslovaco, Dolník (2007), sostiene que la fraseología debe tratarse dentro de la lexicología, sin hacer diferencia entre las unidades fraseológicas y las demás unidades léxicas, pues para él, las unidades fraseológicas forman otro grupo especial de las léxicas y la frontera entre la fraseología y la lexicología es tan imprecisa que apenas es posible hablar de dos disciplinas separadas. Según la metodología, la fraseología se percibe en dos vertientes: la histórica y la comparativa (Mlacek, Durčo, 1995).

A pesar de que la fraseología eslovaca cuenta con una tradición bastante larga y se han publicado numerosos trabajos a nivel teórico y comparativo (eslovaco-ruso, eslovacoalemán, eslovaco-inglés, eslovaco-francés, eslovaco-español), hasta la fecha no existe ninguna obra lexicográfica moderna de la fraseología eslovaca, quedando así como la mejor fuente el diccionario de Smiešková, Malý frazeologický slovník del año 1989 que carece de expresiones nuevas y cuenta aún con bastantes fraseologismos arcaicos, o sea, de uso muy restringido. Por otro lado, podemos destacar algunas obras lexicográficas de la fraseología comparativa del eslovaco con el francés, con el ruso o con el español en forma de diccionarios.

\section{Fraseología en España}

La primera mención paremiológica En España data de la Edad Media, del año 1549. Su autor, Vallés, en su obra Libro de refranes copilado por el orden del abc en el qual se contienen quatro mil y trezientos refranes. El mas copioso que hasta hoy ha salido impresso logró documentar unos 4300 refranes españoles (Ruiz-Gurillo, 1997: 18). Durante siglos seguían apareciendo obras similares, tratándose de meras recopilaciones de las expresiones de la cultura popular que todavía carecían de métodos de investigación científica.

En la fraseología española son importantes los años 50 del siglo pasado cuando, el lingüista Casares definió por primera vez el objeto de estudio de esta disciplina, y elaboró la primera clasificación de las unidades fraseológicas. Su obra Introducción a la lexicografía moderna significó el comienzo del estudio de las expresiones idiomáticas desde el aspecto lingüístico y llegó a representar el punto de partida para los futuros investigadores (Martínez Montoro, 2002). Los lingüistas posteriores han reelaborado y reformulado las postulaciones de Casares, han brindado nuevos puntos de vista a la problemática y han hecho nuevas aportaciones. Sin embargo, muchas de las ideas de Casares siguen vigentes en la actualidad.

En las décadas posteriores, aunque no se publicaron obras tan significativas, los lingüistas se centraron en definir el estatus de la fraseología dentro de la lingüística, sus fronteras con las demás disciplinas, el objeto de estudio y su terminología. En los años 90 del siglo XX salen a la luz los trabajos teóricos de dos lingüistas: en 1996 Manual de fraseología española de Corpas Pastor y en 1997 Aspectos de fraseología teórica española de Ruiz Gurillo. Aunque se trata de obras contemporáneas, ambas investigadoras sostienen actitudes distintas. Corpas Pastor entiende la fraseología en sentido amplio, siendo las unidades en el centro del interés las colocaciones, las locuciones y los enunciados fraseológicos, incluyendo las estructuras de carácter oracional. Ruiz Gurillo se limita a la concepción estrecha y las unidades en el centro del 
interés son las locuciones, las frases proverbiales ${ }^{1}$ y las unidades sintagmáticas, es decir, a nivel de la palabra o del sintagma.

En el presente, forman una nueva área de estudio las unidades fraseológicas en el contexto de un texto determinado, es decir, se pone énfasis en sus aspectos funcionales y del discurso, igual que en su papel en los lenguajes especializados (fraseologismos de una determinada profesión). Estos nuevos retos en la fraseología han nacido gracias al desarrollo de las nuevas corrientes lingüísticas, tales como son la lingüística de corpus y la semántica cognitiva. Un desarrollo paralelo se nota también en el campo del estudio de los fraseologismos en el contexto de la psicolingüística y la lingüística comparada (Corpas Pastor, 2003: 44).

\section{Objetivos, métodos}

En el presente artículo partimos de la concepción propuesta por Corpas Pastor y abarcamos tanto frasemas a nivel de la palabra y del sintagma como a nivel de la oración. El núcleo de nuestro interés lo constituyen aquellas unidades fraseológicas que contienen en su estructura el color rojo, los llamados cromatismos. Hemos elegido el color rojo, por ser un color con un gran número de connotaciones, por lo cual suponemos que también formará parte de bastantes fraseologismos tanto en español como en eslovaco. La psicóloga alemana, Heller, ha realizado una investigación extensa sobre los colores y sus asociaciones. En su libro La psicología del color. Cómo actúan los colores sobre los sentimientos y la razón (2004) podemos encontrar las siguientes connotaciones para el color rojo que se repiten con frecuencia: positivas (amor, pasión, vida, alegría, nobilidad) y negativas (odio, comunismo, agresividad, guerra, prohibición, peligro) (Heller, 2004: 10).

Uno de los criterios de la selección de las unidades fraseológicas para nuestro corpus ha sido (en cuanto al idioma español) el carácter panhispánico de aquellas mismas; es decir que existan tanto en la variante peninsular como en la americana indistintamente, o solo en la europea. Otro criterio de selección ha sido el criterio de la actualidad de dichas unidades. Hemos comprobado su uso en el corpus electrónico CREA (Corpus de referencia del español actual) de la Real Academia Española. Los diccionarios consultados fueron fraseológicos y monolingües. En eslovaco: Slovník súčasného slovenského jazyka (2006), Slovník slovenského jazyka (2003) y Malý frazeologický slovník (1989). En español: Diccionario de la Real Academia Española (2014), Diccionario de uso de María Moliner (2007) y Diccionario fraseológico del español actual (2004). También hemos trabajado con el diccionario fraseológico eslovacoespañol y español-eslovaco de Trup, Bakytová (2017), Španielsko-slovenský a slovensko-španielsky frazeologický slovník. El corpus de nuestra investigación consta de 39 frasemas eslovacos y 20 españoles ${ }^{2}$.

${ }^{1}$ Ruiz Gurillo (1997: 56) se refiere a las frases proverbiales como a una categoría puente, ya que en ocaciones se asemeja a la locución, en ocasiones al refrán, dependiendo si se resalta el fondo (locución) o la figura (refrán): armar la de San Quintín (locución) vs. contigo, pan y cebolla (refrán). Las frases proverbiales equivalentes a la locución denomina frases proverbiales de tipo 1 y las equivalentes a refranes frases proverbiales de tipo 2. En su visión de la fraseología en forma estrecha se refiere, por tanto, a las frases proverbiales de tipo 1.

${ }^{2}$ Cabe mencionar que en ambos idiomas hubo expresiones que presentaban sinónimos dentro de una misma acepción o bajo varias acepciones en las fuentes lexicográficas. Para los fines de nuestra 
El objetivo del presente artículo es analizar las unidades fraseológicas con el componente «rojo» a nivel comparativo entre los idiomas eslovaco y español desde tres aspectos: formal, semántico y traductológico. Desde el aspecto formal nos fijamos en las estructuras más frecuentes en ambos idiomas que es posible formar con este color. Desde el aspecto semántico nos centramos en los significados más frecuentes de dichas expresiones, comparando y contrastándolos a nivel interlingüístico. Desde el aspecto traductológico examinamos los fraseologismos eslovacos con y sin equivalentes en el idioma español. El segundo objetivo es proponer una serie de actividades didácticas que se podrían aprovechar en el aula de ELE en los centros educativos en Eslovaquia.

\section{Análisis comparativo-contrastivo}

\subsection{Aspecto formal}

La mayoría de los fraseologismos en ambos idiomas es de carácter adjetivo-nominal, pues prevalece la estructura de «adj. + sust.» en eslovaco, o de «sust. + adj.» en español. Este esquema predomina en ambas lenguas, pero en eslovaco prevalece en absoluto, ya que 22 de 39 expresiones tenían esta estructura. Mientras tanto, en español fueron solo 7 de 20 expresiones.

Otra estructura muy frecuente era la comparativa que en eslovaco tiene la forma de «červený (rojo) + ako (como) + sust.» y cuenta con 13 fenómenos a los que es posible aplicar tales expresiones. En español las comparaciones son de dos tipos: el primero es idéntico a la forma eslovaca, «rojo + como + sust.» y el segundo tipo es «más + rojo + que + sust.» En eslovaco, la parte llamada comparatum está expresada por varios lexemas sinónimos donde algunos funcionan como sinónimos dentro de un mismo frasema con significado más restringido, relacionado con la cara humana. Otros funcionan como sinónimos dentro de un frasema con significado más extenso, hablando del aspecto físico de una persona. Los diccionarios eslovacos llevan una marca lexicográfica que especifica el significado y el uso de estas variantes. Así, una persona puede estar roja como un pimiento (paprika)/un tomate (paradajka)/el cangrejo (rak)/el pavo (moriak) debido a la vergüenza o ira. Estas expresiones son aplicables exclusivamente para el color de la cara humana. Asimismo, una persona puede tener el cabello rojo como una lumbre (plameň)/el fuego (ohě̌) y puede tener la nariz roja como una remolacha (repa/cvikla). O una persona puede estar roja como la sangre $(k r v)$. Esta última expresión tiene el significado extendido, pues denota tanto a una persona como a una cosa. En todas estas comparaciones se trata del significado de muy o demasiado rojo o que se asemeja al rojo, en su mayoría, en sentido peyorativo. Pero una persona también puede ser/estar roja como una fresa (jahoda)/una frambuesa (malina)/una rosa (ruža)/una peonía (pivónia). Esta comparación se restringe al comparandum «rostro» en sentido de bien rojo/hermoso, y se aplica exclusivamente a un chico o una chica hermosa. Lo más frecuente es que combinen con los verbos «estar»/«ser»/«tener». El último verbo requiere siempre un complemento directo (rostro, cara, mejillas, labios).

investigación, hemos considerado cada sinónimo como una expresión individual, aunque formaba parte de una misma. Por esta razón, el número de frasemas en este artículo puede variar del número de los frasemas en los diccionarios. 
En español hay lexemas ligados solo a las estructuras con el nexo «como»: rojo como la acerola/la amapola/el guindo y otros ligados solo a estructuras con el nexo «más que»: más rojo que el fuego/el sol/la lumbre/un pimiento. Luego, los comparatio tomate y grana pueden emplearse en ambas estructuras indistintamente. Los lexemas nominales que colocan con el adjetivo «rojo» van con el artículo definido o indefinido. No hay ninguna regla gramatical que imponga el empleo de uno u otro tipo de artículo y hay que respetar la estructura tal como es para no violar la unidad de una expresión fraseológica. Solo en casos particulares es posible esta conmutación: por ejemplo, el lexema grana se une con el artículo definido en rojo como la grana, pero con el indefinido en más rojo que una grana. Los verbos con los que estas expresiones suelen

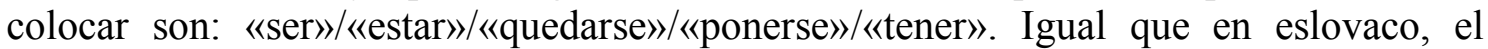
verbo «tener» requiere un complemento directo.

\subsection{Aspecto semántico}

Algunos lingüistas distinguen entre los términos «campo léxico» y «campo semántico», aunque ambos los definen como un conjunto de unidades léxicas con rasgos semánticos comunes. También Gómez-Pablos, hace esta distinción: «Por campo semántico se entiende el conjunto de palabras que tienen la misma categoría gramatical y comparten al menos un rasgo semántico (...). Por campo léxico se entiende el conjunto de palabras de diferentes categorías que están relacionadas con un mismo tema» (Gómez-Pablos, 2016: 118-119). Muchos lingüistas, sin embargo, emplean ambos términos indistintamente. Nosotros hablamos de los campos semánticos, ya que dentro de cada campo se trata de expresiones de la misma categoría gramatical. Hemos definido los siguientes campos: COMUNISMO, RABIA/IRA, ALERTA/PELIGRO/IMPORTANCIA. Además, hubo unidades con significado singular que no fue posible considerar dentro de un campo, por eso los tratamos por separado.

El significado más frecuente de los frasemas eslovacos es el de comunismo - 12 expresiones y 6 de ellas son aplicables a personas: červený komisár (comisario rojo), červená garda (garda roja), červené vojsko (ejército rojo), červené odbory (sindicatos rojos), Červená armáda (Ejército Rojo), červené brigády (brigadas rojas) y otras 6 a cosas u otras realidades: červená totalita (totalidad roja), červený teror (terror rojo), červená nomenklatúra (nomenclatura roja), červená knižka (librito rojo), červené noviny (periódico rojo), červený kútik (rinconcito rojo). Fijémonos que en casi todas estas unidades se ha producido el cambio semántico del adjetivo «rojo (červený)», mientras que los sustantivos han conservado sus significados originales. Por tanto, podemos decir que estas unidades son semitransparentes, es decir, no poseen un alto grado de opacidad y su significado se puede deducir con bastante facilidad. La única excepción dentro de esta categoría es el frasema červený kútik donde se ha producido el cambio semántico de ambos componentes, tanto adjetival como nominal. El origen de este frasema hay que buscarlo en los antiguos eslavos. Ellos denominaban červený kút [(rincón rojo) - červený viene del antiguo eslavo con el significado de hermoso] el así llamado «rincón santo», para los eslavos orientales el lugar más importante del hogar en el que estaban ubicados los íconos. Más tarde, durante la era comunista, el significado original pasó de moda, pero empezaron a crearse los rinconcitos rojos (červené kútiky), en función de «santuarios soviéticos». Se establecían en las instituciones de trabajo, 
eran adornados por los retratos de los fundadores de esta ideología, se encontraba en ellos la literatura marxista y materiales de los congresos comunistas (Klimontovič, 2004). Este último significado ha penetrado a la fraseología eslovaca, entendiéndose bajo este término instalaciones educativo-culturales del Movimiento sindical revolucionario de la antigua República Socialista Checoslovaca (Slovník súčasného slovenského jazyka, 2006). Esta expresión es, por tanto, totalmente idiomática, muy poco transparente y con un alto grado de opacidad. En español, al contrario, las fuentes lexicográficas no registraban ninguna expresión fraseológica que se refiriera al comunismo. Tal resultado se puede explicar a base del contexto histórico cuando Eslovaquia formaba parte de la antigua URSS y porque la cercanía geográfica de Eslovaquia y Rusia es más considerable que la de España y Rusia. En España, tampoco se había implicado el régimen comunista.

Otro significado muy frecuente fue el de rabia o ira, encontrado en 7 expresiones españolas: al rojo vivo, poner rojo a alguien, rojo como el tomate, más rojo que el fuego/una lumbre/un pimiento/un tomate y en 4 eslovacas: červený ako rak (cáncer)/moriak (pavo)/paprika (pimiento)/paradajka (tomate). Todas estas expresiones tienen como sujeto (agente o paciente) siempre a una persona, ya que se trata de una cualidad humana. En términos de los lingüistas norteamericanos, Lakoff y Johnson (2017), se trataría de un ejemplo de metáfora ontológica, quiere decir, el cuerpo humano se percibe como una sustancia o un recipiente con una sustancia que, bajo ciertas condiciones (la rabia), puede encenderse (nos ponemos casi rojos). Algo menos numerosas fueron las connotaciones con alerta/peligro/importancia. En eslovaco encontramos 4 ejemplos: červená kniha (libro rojo), červené čísla (números rojos), niečo sa tiahne niečím ako červená nit’ (algo pasa por algo como un hilo rojo), červený koberec (alfombra roja); y en español igualmente 4 ejemplos: números rojos, alerta roja, teléfono rojo y alfombra roja.

En el último grupo englobamos aquellos fraseologismos que no hemos podido asignar a ninguno de los campos semánticos definidos. En eslovaco hay una expresión figurativa červený kohút (gallo rojo) que, en un alto grado de metaforización, se refiere a un incendio; probablemente por la semejanza del color llamativo de las plumas de los gallos con el color de las llamas y también por la semejanza de forma de la cresta o las hoces de la cola de gallo con la de las llamas. Bajo acepciones individuales figuraban en los diccionarios eslovacos dos variantes de esta expresión: červený kohút na streche (gallo rojo sobre el techo) y červený kohút zakikirikal (gallo rojo acaba de cantar). La primera expresión equivale a la palabra «incendio», mientras la segunda a «encenderse». El empleo de la palabra «strecha (techo)» en este frasema podemos explicar a través del modo de vida tradicional de los campesinos eslovacos quienes construían sus casas de madera con el techo de paja, material que prendía con facilidad. En la fraseología eslovaca encontramos también la expresión červený majster (maestro rojo) para referirse a un verdugo. Deducimos esta denominación de la asociación de su profesión con la sangre y del color de la máscara que llevaban los verdugos medievales en los tiempos de la monarquía austro-húngara, que era de color rojo. Podemos decir que se trata de un eufemismo para suavizar una realidad negativa, el oficio de los verdugos. Por último, es interesante el frasema eslovaco mávat' pred niekým červeným súknom (agitar con una tela roja delante de alguien) que corresponde al significado de «provocar a alguien». Es posible que este sentido deriva del comportamiento de los 
machos de algunos animales que reaccionan furiosamente al ver algo de color rojo. Es curioso que la fraseología española no refleje tal imagen de la realidad extralingüística.

\subsection{Equivalentes traductológicos}

En la terminología y taxonomía de los equivalentes traductológicos seguimos a la lingüista Sekaninová (1993), que diferencia dos clases básicas de estos equivalentes: absolutos y relativos. Hablamos de equivalentes absolutos simétricos en el caso de los frasemas červené čísla - números rojos, porque tienen la misma estructura, significado y también motivación. Para los estudiantes de ELE podrían ser confusos los «falsos amigos» libro rojo - červená kniha que, a primera vista parecen equivalentes absolutos, ya que concuerdan en la estructura, sin embargo, sus significados difieren: mientras que en eslovaco se refiere al libro donde se recogen las especies de fauna y flora en peligro de extinción en la Tierra, en español se trata de un documento diplomático, publicado por el Gobierno en ocasiones especiales. Hay concordancia de forma, pero diferencia de significado.

La situación cambia en la expresión červená knižnica que tiene equivalente en español, sin embargo, el elemento cromático no es el color rojo sino rosa, dando lugar a la expresión novela rosa. Además, difieren también en el elemento nominal: en eslovaco el significado es más genérico y se refiere al conjunto de la literatura amorosa que funciona como hipónimo del hiperónimo «knižnica (librería)»; en español el significado se limita a un tipo concreto de esta literatura. Hay concordancia de significado, aunque las formas son distintas. Lo mismo sucede con las expresiones červený trpaslík estrella enano, denominación de una estrella que es mucho menos radiante que el Sol, pero mucho más grande que cualquier otro planeta (Slovník súčasného slovenského jazyka, 2006). En eslovaco, el grado de opacidad e idiomaticidad es mayor que en español.

En las fuentes lexicográficas eslovacas figuran las unidades červená vlna y červený koberec, con el significado de pillar varios semáforos con la luz roja sucesivamente (la primera) y con el de una alfombra extendida en ocasiones especiales para los personajes famosos o importantes - políticos, artistas, etc.-(la segunda). Como se puede comprobar en varios corpus electrónicos de la lengua española o en la web, se trata de expresiones bastante usadas en el español actual. Por tanto es de extrañarse, que las fuentes lexicográficas españolas no recojan estas expresiones. En Internet las hemos encontrado como equivalentes absolutos simétricos de las unidades eslovacas con la forma idéntica: ola roja y alfombra roja. En este caso, la concordancia de forma y significado hace que dichas unidades no supongan una dificultad para los estudiantes eslovacos del español a la hora de entender y traducirlas.

Por último, lo que comprende la equivalencia de traducción de las construcciones comparativas, se trata de equivalentes absolutos simétricos en aquellos tipos, donde la comparación se forma mediante los sustantivos paradajka, paprika (tomate, pimiento). En ambos idiomas sirven para expresar ira o vergüenza. Otros equivalentes absolutos simétricos son los lexemas ohen̆, plamen̆ (fuego, lumbre) para referirse al color rojizo de la cara debido a cualquier motivo negativo, sin especificarlo. Finalmente, para describir a alguien guapo, con las mejillas coloradas, en ambos idiomas se hace uso de 
sustantivos que evocan algo agradable, bonito, dulce o de buen olor, aunque los significados de tales lexemas difieren en dichos idiomas.

\subsection{Aplicaciones didácticas}

La gramática y el léxico son los pilares básicos en la adquisición de un idioma, sin embargo, el proceso de enseñanza de lenguas no debería limitarse solo a estos dos bloques. La adquisición de un idioma comprende también aprender a entender a los nativos y saber desenvolverse en situaciones cotidianas. Y una parte indispensable de ello es el conocimiento de la fraseología, porque muchas expresiones fraseológicas forman parte del habla diaraia, aunque los usuarios del idioma muchas veces ni se dan cuenta de eso.

Generalmente, las clases de ELE no ofrecen mucho espacio a las expresiones idiomáticas, y si aparecen, se tratan como vocabulario «de más», abarcando un par de expresiones relativas al tema que se está abordando. Pero no se presentan a los estudiantes en un contexto más amplio, incluso se suele pasar de presentárselas en términos de «lo fraseológico», «lo idiomático» y solo sirven para ampliar el vocabulario en función de sinónimos de un tema concreto (Ruiz Gurillo, 2000: 259). Se suele dar un poco de espacio a la introducción de la fraseología en las clases de ELE en los niveles más avanzados (a partir de B1 y más). Pero se empieza con la fraseología ya en los niveles A1-A2 y el alumno aprende el primer tipo de unidades - colocaciones de esquemas frequentes: "sust. + sust.» (gafas de sol) o "verbo + sust.» (hacer deporte). Tales expresiones son necesarias en casos donde no es suficiente con una expresión univerbal (D'Andrea, 2018: 188). En este lugar, Ruiz Gurillo apunta que un buen manual debería abordar el tema de la fraseología desde el enfoque comunicativo, introduciendo los fraseologismos según los campos léxicos o sus peculiaridades sintácticas (Ruiz Gurillo, 2000: 260).

En las últimas décadas se suele hablar más sobre la necesidad de emplear la fraseología en la didáctica de idiomas. Así ha surgido la disciplina que se ocupa de estas cuestiones -la didáctica de la fraseología-; o hay fuentes que operan con el término de fraseodidáctica, considerándose esta disciplina como una rama de la fraseología aplicada (Gónzales Rey, 2012: 67). En este sentido, fue a finales de los años setenta y durante los ochenta, cuando empezaron a surgir numerosos trabajos tratando el problema de la enseñanza de la fraseología de un idioma extranjero a los estudiantes de otros idiomas. En el contexto de Eslovaquia (por aquel entonces Checoslovaquia), el hispanista eslovaco, Škultéty, publicó en 1978 un artículo El papel de los modismos en la enseñanza del español (Gónzales Rey, 2012: 71). Es considerado el pionero en aplicar las cuestiones didácticas en la enseñanza del español en los estudiantes eslovacos. En el contexto del español, con el llamado «boom» en la investigación fraseológica en los años noventa, surgen numerosos trabajos dedicados a las cuestiones tanto teóricas como prácticas de la fraseología. A finales de esta década aumenta el número de trabajos que se ocupan de la enseñanza del español a los extranjeros. Tal tendencia ha sido impulsada por el aumento de los estudiantes extranjeros del español y sus necesidades particulares. Todo esto emerge del carácter multinacional del español, una lengua con gran peso económico en el comercio internacional (García Delgado y Jiménez, 2015 en Anuario del Instituto Cervantes, 2018). 
A continuación, esbozamos una serie de actividades didácticas mediante los cuales es posible trabajar cierto tipo de fraseologismos en las clases de ELE en los centros educativos eslovacos; atendiendo al tema que habíamos desarrollado antes en teoría, se trabajan los cromatismos con el color rojo. Pero antes de elegir cualquier tipo de práctica libre (es decir, fuera del libro de texto) de la fraseología que el docente desee trabajar con sus estudiantes, debería considerar estos aspectos: la actualidad y la frecuencia de uso de los fraseologismos, su variabilidad geográfico-cultural (por ejemplo, no confundirlos con las variantes hispanoamericanas) y debería pensar también en la relación de dichos frasemas con el mundo real de sus estudiantes; quiere decir, no solo deben ser usadas en el español actual, sino que deben corresponder a los intereses y conocimiento del mundo de los estudiantes, ya que no da igual enseñar el mismo tema a través de las mismas actividades a un grupo de adolescentes que a un grupo de adultos. En fin, la propuesta que presentamos está destinada a los estudiantes eslovacos prácticamente de cualquier tipo de centro educativo (colegios, escuelas de idiomas) siempre que tengan un nivel B1+ de español como mínimo. Incluir la fraseología en la enseñanza tiene varios beneficios para el alumno: se representa la lengua real, el uso vivo de la lengua, la «cultura con k», de modo igual que los textos literarios; de modo similar que las canciones o poemas, se introduce el factor lúdico y emocional, lo que fomenta la dinámica en el aula y ayuda a que los alumnos recuerden mejor la materia.

Siempre es conveniente empezar con algunas actividades de precalentamiento que sirven para inducir al alumnado al tema. En este sentido, proponemos empezar con una actividad de precalentamiento (Actividad 1) del siguiente tipo: el profesor pregunta a sus alumnos por las asociaciones que tienen con el color rojo. Esta actividad se hace oralmente y ocupa menos de 5 minutos, pues se supone que sea dinámica y los alumnos lancen espontáneamente sus asociaciones personales. Sigue otra actividad de precalentamiento (Actividad 2), directamente entrelazada con la anterior, pero es mejor hacerla por escrito. El profesor pretende limitar el pensamiento de sus alumnos y centrarlo en el mundo hispano y eslovaco. En la pizarra esboza una tabla con tres columnas y apunta las asociaciones del color rojo del mundo hispano-eslovaco que los estudiantes digan. Mediante estas dos actividades los estudiantes ganan el interés por el tema, dándose cuenta de la alta frecuencia de este color en la vida. Debería ocupar menos de 10 minutos.

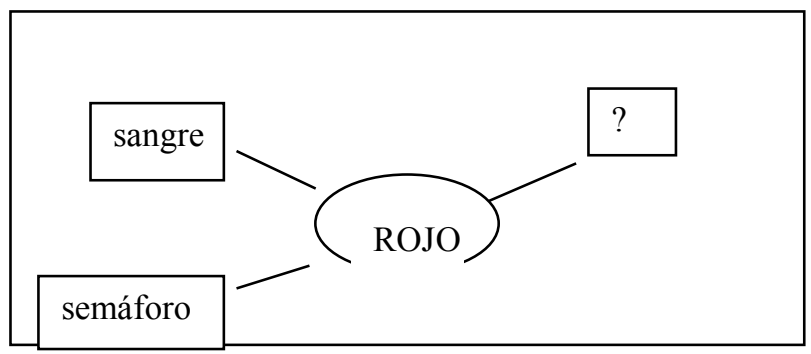

Figura 1. Actividad de precalentamiento - asociaciones generales 


\begin{tabular}{|c|l|l|}
\hline \multicolumn{1}{|c|}{ España/Hispanoamérica } & \multicolumn{1}{|c|}{ ambos países } & \multicolumn{1}{c|}{ Eslovaquia } \\
\hline banderilla del toreador & $\begin{array}{l}\text { Caperucita Roja (Červená } \\
\text { čiapočka) }\end{array}$ & $\begin{array}{l}\text { el color del antiguo partido } \\
\text { comunista }\end{array}$ \\
\hline $\begin{array}{l}\text { color típico de los trajes de } \\
\text { flamenco }\end{array}$ & $\begin{array}{l}\text { uno de los colores de la } \\
\text { bandera nacional }\end{array}$ & $\begin{array}{l}\text { parte del nombre propio de } \\
\text { algunos pueblos eslovacos }\end{array}$ \\
\hline$?$ & \multicolumn{1}{|c|}{$?$} \\
\hline
\end{tabular}

Figura 2. Actividad de precalentamiento - asociaciones particulares

En el tercer ejercicio (Actividad 3) el enfoque yace en que el alumno se dé cuenta del significado de las expresiones particulares. Es un tipo de ejercicio estructurado, así que no debería haber muchas posibilidades de equívocos e induce al estudiante intuitivamente a la temática. Se recomienda dar un poco tiempo a los alumnos que lean las posibilidades y dependiendo del nivel del grupo, pueden realizarla junto con el profesor o solos. Debería ocupar menos de unos 5 minutos.

\section{Actividad 3. ¿Qué definición corresponde a cada uno de estos frseologismos?}
A. al rojo vivo
B. poner rojo a alguien
C. ponerse rojo como el tomate
D. libro rojo
E. alerta roja
F. teléfono rojo

1. Situación de máxima atención y vigilancia.

2. En estado de máxima tensión o excitación debido a la irritación.

3. Avergonzar a una persona.

4. Libro que contiene documentos diplomáticos publicado en determinadas ocasiones por los gobiernos, para informar los órganos legislativos o al público.

5. Ruborizarse debido a la vergüenza.

6. Línea telefónica directa para consultas de alto nivel en casos de emergencia.

Figura 3. Ejercicio estructurado - aspecto semántico

Entrelazando con el ejercicio anterior, en el cuarto ejercicio (Actividad 4) los alumnos se dan cuenta del uso real de la lengua en contextos y se van fijando en la forma de las expresiones. Aquí se requiere consultar un corpus (por ejemplo, el Corpus de referencia del español actual de la RAE). Los alumnos reciben ficheros donde pone en una casilla la plabra «rojo» y a la derecha e izquierda habrá casillas vacías. Los alumnos trabajan individualmente o en parejas y van apuntando las concordancias que consideran nuevos, interesantes, etc. Si desconocen algo, preguntan al profesor por el significado y pueden apuntarlo al lado de la expresión española. Después de unos 10 minutos se comparan entre todas las colocaciones en contextos más frecuentes o interesantes que los alumnos han encontrado. Aquí depende si los estudiantes saben ya trabajar con un corpus o no. Si no, se requiere tiempo extra para la explicación y ejemplificación por parte del profesor. Aunque sea novedoso para los estudiantes, no debería ser problemático, ya que manejan muy bien las nuevas tecnologías. 


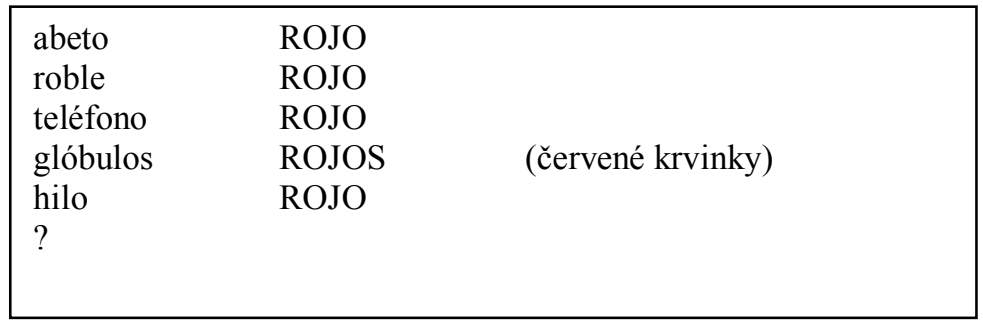

Figura 4. Trabajo con el corpus

Los estudiantes se dan cuenta del uso en contexto de las expresiones cromáticas en ejercicio donde hay que completar frases con el cromatismo correcto, según el significado (Actividad 5). Es una actividad estructurada, pues no debería presentar muchas dificultades ni posibilidades de errar. Similarmente funciona el otro ejercicio estructurado (Actividad 6 ) en el que el estudiante tiene que distinguir entre el significado literal e idiomático según el contexto. Junto deberían ocupar estos ejercicios menos de 10 minutos y pueden hacerse o por turnos individuales, en parejas o todos a la vez.

Actividad 5. Complete las frases con la unidad fraseológica adecuada en su forma correspondiente:
a. carne roja
b. farolillo rojo
c. piel roja
d. al rojo vivo

e. ponerse rojo como el tomate f. poner rojo a alguien

1. Ana, al ver que Mauricio no dejaba de mirarla,

2. Mejor no me inscribo en esta competición. No soy un buen corredor, pues no me gustaría ser el

3. El médico te desaconseja comer la

4. Los agricultores están porque se han enterado que va a subir el precio del gasóleo.

5. Existen reservaciones donde siguen viviendo las, habitantes indígenas.

6. Pobre Santiago. ¿Has visto cómo en la defensa del trabajo?

Figura 5. Cromatismos en contexto - huecos

Actividad 6. Distingue en las siguientes frases entre el significado literal y fraseológico:

1A. Antes teníamos un teléfono rojo, ahora tenemos uno negro.

1B. El conflicto diplomático persistía, el teléfono rojo en ambos países no dejaba de sonar.

2A. Algunos ministros se han opuesto al último artículo del libro rojo publicado el mes pasado.

2B. No recuerdo el título, pero sé que era un libro rojo, de tapa dura.

3A. Íñaki, el piel roja huérfano, poco a poco iba acostumbrándose a la cultura europea.

3B. Retírate ya del sol; que ya tienes la piel roja, te vas a quemar.

4A. Mira, tienes que contar los números negros; los números rojos ya son los resultados.

4B. Es muy desagradable encontrarse con la cuenta en números rojos. 
$5 \mathrm{~A}$. Me regalaron un farolillo rojo muy bonito que se puede encender.

5B. Otra vez has sido el farolillo rojo de la competición.

Figura 6. Cromatismos en contexto - parejas

Los siguientes dos ejercicios son parecidos: primero, los estudiantes deducen el significado de los cromatismos españoles y observan la equivalencia en eslovaco (Actividad 7). Segundo hacen lo mismo de manera inductiva, buscando equivalentes en la lengua meta - el español (Actividad 8). Los alumnos se dan cuenta del aspecto formal del estos cromatismos y distinguen entre lo idiomático y no idiomático. Dependiendo de muchos factores (el número de los alumnos, la dinámica del grupo, el nivel de los alumnos) hace que estas actividades se hagan en conjunto o por parejas y debería ocupar menos de 10 minutos.

Actividad 7. ¿Existen estos fraseologismos también en tu idioma? ¿Si es así, qué forma tienen? ¿Cuáles son idiomáticos y cuáles no lo son?

piel roja

al rojo vivo

alerta roja

poner rojo a alguien

farolillo rojo

libro rojo

Figura 7. Equivalentes - forma deductiva

Actividad 8. ¿Cómo podrías traducir los siguientes fraseologismos eslovacos al español?

červená knižnica

červená kniha

červené čísla

červený majster

Červená armáda

červené noviny

Figura 8. Equivalentes - forma inductiva

La penúltima actividad que proponemos (Actividad 9) es apta para realizarla en forma de «roll play». Los alumnos en parejas estimulando situaciones reales en las que tienen que utilizar al menos uno de los cromatismos con el color rojo que sea conveniente en cada situación. A través de pequeños microtextos los estudiantes intentan usar las unidades del idioma en la vida real. Se necesitan unos 5 minutos para la preparación y como máximo otros 5 minutos para el turno de cada pareja. Durante todo el tiempo, el profesor hace de moderador: los alumnos pueden hacerle preguntas mientras se preparan su turno y luego el profesor modera el tiempo aproximado de cada pareja. El profesor interrumpe al alumno solo en casos necesarios, porque deja que el alumno practique su competencia comunicativa y se desenvuelva en situaciones cotidianas.

Actividad 9. En cada una de estas situaciones, intenta emplear algunos fraseologismos que se te presentan a continuación. Puedes usar más de una expresión y pueden repetirse.

ser el farolillo rojo, ponerse rojo como el tomate, poner rojo, estar al rojo vivo, estar rojo como la amapola, quedarse más rojo que un pimiento 
1. Después de una competición en la clase de educación física tu profesor comenta los resultados diciéndote que otra vez has sido el/la último/a de la clase. Cuenta a tus padres cómo te sientes.

2. Ves que tu amigo/a empieza a intimarse con tu pareja. Cuenta a tu mejor amigo/a tus sensaciones.

3. Obtienes una nota muy mala de un examen de gran peso. Intentas explicarlo a tu madre, sin embargo, ella está muy enfadada contigo. Al día siguiente, cuentas a tu amigo/a la reacción de tu madre.

4. En una asignatura, el profesor te llama, y tú no sabes mucho de la materia... Tu evaluación no es muy positiva y el profesor te lo dice delante toda la clase. Imagina cómo te sientes.

5. Acabas de salir con un/a chico/a que te gusta mucho. Te sientes entusiasmado/a y lo cuentas a tu mejor amigo/a.

Figura 9. Roll play

Concluimos con la última actividad (Actividad 10) dedicada a la escritura creativa. Es conocido que muchos temen a escribir algo, es bueno si se trabaja en pareja. Se practica la cooperación y los alumnos pueden inspirarse uno al otro. Es una actividad buena para el desarrollo de la expresión escrita y, por tanto, de la comprensión auditiva, ya que cada alumno tiene que escuchar a sus compañeros cuando leen sus historias. Dependiendo del tiempo que tiene el profesor y de lo que duran las clases en cada centro educativo, los estudiantes pueden realizar la tarea escrita como tarea y presentarlas en la clase siguiente.

Actividad 10. Intenta continuar la historia, pero que sea de manera diferente de cualquier versión oficial.

Érase una vez una niña que siempre llevaba una capa roja con capucha. Por eso, todo el mundo la llamaba Caperucita Roja. Caperucita vivía en una casita cerca del bosque. Un día, su madre le dijo: - Hija mía, tu abuelita está enferma. (...)

Figura 10. Escritura creativa

\section{Conclusiones}

El objetivo del presente artículo ha sido analizar y comparar las unidades fraseológicas eslovacas y españolas con el componente cromático «rojo» en su estructura con el fin de aplicar esta parte de la lingüística en las clases de ELE en el contexto de los centros educativos eslovacos. Para llegar a cumplir con el objetivo establecido, hemos sometido las expresiones previamente seleccionadas de varias fuentes lexicográficas al análisis desde el aspecto formal, semántico y traductológico para poder desarrollar su aplicación didáctica para los estudiantes eslovacos de ELE.

En los sistemas lingüísticos de ambos idiomas predomina la estructura de «adjetivo + sustantivo» (el eslovaco), o bien, «sustantivo + adjetivo» (el español). En eslovaco, 22 de 39 frasemas están formados mediante esta estructura, en español el número es algo más bajo, 7 de 20. La segunda estructura sintáctica más frecuente es la construcción comparativa, siguiendo el esquema de «comparandum + nexo + comparatio», donde en la parte llamada comparatio se pueden emplear varios lexemas sinónimos para un mismo significado. En español, este esquema es algo más complejo, ya que cuenta con 
dos subtipos: «más + rojo + que» y «rojo + como», en función del grado neutral y comparativo. También en la lengua eslovaca es posible expresar los mismos significados y gradar el adjetivo «červený», no obstante, a diferencia del español, la estructura sintáctica no cambia: «červený ako» y «červenší ako/než». Por ser el eslovaco una lengua sintética, la marca de la gradación está en la desinencia del adjetivo, en el sufijo - Ši unido a la base. El español, al ser una lengua analítica, utiliza para la gradación lexemas ortográficamente autónomos. En español, a diferencia del eslovaco, la complejidad es mayor también en el sentido de emplear lexemas sinónimos, dependiendo si se usan con el artículo definido o indefinido; por ejemplo, más rojo que el fuego, pero más rojo que un tomate. Por otro lado, un mismo lexema se puede combinar tanto con el artículo definido como indefinido y el empleo de uno u otro viene establecido por el tipo de estructura en la que se usa; por ejemplo, rojo como el tomate, pero más rojo que un tomate.

Desde el aspecto semántico, podemos afirmar que en la fraseología eslovaca, la connotación más frecuente de los cromatismos del color rojo es la del régimen comunista. Hasta 12 unidades pluriverbales tenían esta connotación y todas obedecían a la estructura de «adjetivo + sustantivo». Estas expresiones, a la vez, forman el campo semántico con el mayor número de unidades. Como hemos visto en el párrafo anterior, abundan en ambos idiomas estructuras comparativas con el comparandum «rojo» que pueden tener connotaciones tanto positivas como negativas. En cuanto a las negativas, lo más habitual es la relación con el aspecto de la cara humana debido a la ira o vergüenza. Los lexemas que expresan esta relación son: tomate (paradajka), pimiento (paprika), fuego (oheň), lumbre (plameň). En las connotaciones positivas, ambos idiomas recurren a la imagen de frutas como guindo, grana, acerola o malina (frambuesa), jahoda (fresa); y flores como pivónia (peonía), ruža (rosa), amapola. De ahí, la motivación de estos cromatismos es la misma en ambos idiomas. Resulta interesante el frasema eslovaco kývat'mávat' (pred niekým) červeným súknom, literalmente, «agitar con la tela roja delante de alguien», evocando la imagen extralingüística de la corrida de toros, algo propio y característico de España. Por tanto, es extraño que en la fraseología española no exista una expresión similar motivada por esta realidad, es decir, con el significado de provocar a alguien hasta que embiste de rabia.

Respecto al aspecto traductológico de los cromatismos examinados, hemos encontrado solo un equivalente absoluto simétrico: červené čisla - números rojos. Otro subtipo de equivalentes absolutos es: červená knižnica - novela rosa, donde se trata de la misma motivación, pero diferente forma. Equivalentes descriptivos relativos son las expresiones červený trpaslík - estrella enana. Desde el punto de vista traductológico es interesante también la expresión červená kniha - libro rojo, donde la misma forma expresa dos significados diferentes. Desde el punto de vista lexicológico, se puede hablar de los así llamados «falsos amigos» que comprenden aquellas palabras o unidades léxicas que concuerdan formalmente en dos idiomas distintos, pero tienen significados diferentes.

Por último, hemos presentado una serie de actividades didácticas en las que hemos implementado la adquisición de la forma, del significado, de la equivalencia en la traducción del y al segundo idioma de los cromatismos con el color rojo y de su uso en la vida real a través de unos microcontextos. Todas las actividades se pueden trabajar de varias maneras, dependiendo siempre de la situación actual en la clase (el número de los 
alumnos, su voluntad de trabajar, la dinámica del grupo, el grado de dificultad que presentan para ellos los ejercicios, etc.). Están planteadas de modo que fomenten tanto las cuatro destrezas lingüísticas como el aspecto comunicativo, no olvidando la importancia del trabajo en parejas o equipo para la resolución de un problema que se les plantee a los alumnos.

\section{Bibliografía}

CORPAS PASTOR, G. (1996). Manual de fraseología teórica española. Valencia: Gredos.

CORPAS PAStor, G. (2003). Diez años de investigación en fraseología: análisis sintáctico-semánticos, contrastivos y traductológicos. Barcelona: Iberoamericana Ediciones Vervuert, S. L.

ČERMÁK, F. (2007). Frazeologie a idiomatika česká a obecná. Praha: Karolinum.

D'ANDREA, L. (2018). «La fraseología y el uso auténtico de la lengua en el aula de E/LE». En Bargalló Escrivá, M., Forgas Berdet, E., Nomdedeu Rull, A. (eds.), Léxico y cultura en LE/L2: corpus y diccionarios. Tarragona: ASELE, 185-194.

DoLník, J. (2007). Lexikológia. Bratislava: Univerzita Komenského.

Gómez-PABLos, B. (2016). Lexicología española actual. Nümbrecht: Kirsch-Verlag.

GonZALes ReY, Mª I. (2012). «De la didáctica de la fraseología a la frase-odidáctica», Paremia, 21, 67-84.

Heller, E. (2004). La psicología del color. Cómo actúan los colores sobre los sentimientos y la razón. Barcelona: Gustavo Gili.

INSTITUTO CERVANTES (2018). «El español: una lengua viva». Anuario del Instituto Cervantes. Informe. Recuperado el 22/01/20 de: https://cvc.cervantes.es/lengua/anuario/anuario_18/informes_ic/p03.htm\#np39n.

JAROŠOvÁ, A., BuZÁSSYOVÁ, K. (2006). Slovník súčasného slovenského jazyka. Zväzok $A-G$. Bratislava: Veda.

KaČAla, J., PisÁrČIKovÁ, M., PovaŽAJ, M. (2003). Slovník slovenského jazyka. (4. dopl. a upr. vyd.) Bratislava: Veda.

KLimontoviČ, N. (2004). Krasnyj ugol i krasnyj ugolok. Recuperado el 18/10/18 de: https://www.gazeta.ru/comments/2004/04/a_103974.shtml.

LAKOFF, G., Johnosn, M. (2017). Metáforas de la vida cotidiana. Madrid: Catedra.

MARTínez Montoro, J. (2002). «La fraseología en J. Casares», Estudios de Lingüistica, 16, 139-188.

MlaCeK, J. (1984). Slovenská frazeológia (2. vydanie). Bratislava: Slovenské pedagogické nakladatel'stvo.

MlaCeK, J., ĎURČO, P. (1995). Frazeologická terminológia. Recuperado el 15/02/20 de: www.juls.savba.sk/ediela/frazeologicka_terminologia/.

REAl ACAdemia EsPañola (2014). Diccionario de la lengua española. 23. a ed. Recuperado el 26/09/2018 de: http://www.rae.es. 
RuIZ Gurillo, L. (1997). Aspectos de fraseología teórica española. Valencia: Universitat de Valencia.

Ruiz GuRILlo, L. (2000). "Un enfoque didáctico de la fraseología española para extranjeros», Quaderns de Filologia. Estudis Lingüístics, 5, 259-275.

Seco, M., AndrÉs, O., Ramos, G. (2004). Diccionario fraseológico documentado del español actual. Locuciones y modismos españoles. Madrid: Aguilar.

SEKANINOVÁ, E. (1993). Dvojjazyčná lexikológia v teórii a praxi. Bratislava: Veda.

SMIEŠKOVÁ, E. (1989). Malý frazeologický slovník (5. vydanie). Bratislava: SPN.

SPIŠIAKOVÁ, M. (2003). «Fraseología en México», Philologia, 16, 67-73.

SPIŠIAKOVÁ, M. (2016). «El análisis contrastivo del uso, significado y connotaciones de los colores en la lengua eslovaca y española $=$ The contrastive analysis of the use, meaning and connotations of the colors in the Slovak and Spanish language». XLinguae, 9, 104-128. SCOPUS DOI: 10.18355/XL.2016.09.03.104-128

SPIŠIAKOVÁ, M. (2016). El español actual. La unidad y la variedad. Nümbrecht: Kirsch-Verlag.

ŠKULTÉTY, J. (1991). Súčasný španielsky jazyk - španielska frazeológia. Bratislava: Univerzita Komenského.

TRUP, L., BAKYTOVÁ, J. (2017). Španielsko-slovenský a slovensko-španielsky frazeologický slovník. Bratislava: Mikula.

VV.AA. (2007). Diccionario de uso del español María Moliner ( $3^{\text {a }}$ edición). Madrid: Gredos.

Tento príspevok je súčast'ou riešenia grantového projektu VEGA č. 1/0107/18 Chromatizmus a jeho konotácie v kontexte slovanských a románskych jazykov.

Este artículo forma parte del proyecto VEGA 1/0107/18: Cromatismo y sus connotaciones en el contexto de las lenguas eslavas y románicas. 